\title{
A review on Properties of Fiber Reinforced Cement-based materials
}

\author{
ShashwatSharda ${ }^{*}$, , a, Manvendra Singh ${ }^{1, b}$ andSarbjeet Singh ${ }^{1, \mathrm{c}}$ \\ 1 Department of Civil Engineering, Malaviya National Institute of Technology, Jaipur, Rajasthan, India
}

\begin{abstract}
Mixing of horsehair and straw with the clay to form floor and bricks was one of the earliest example in which fiber was utilized to strengthen a brittle matrix. Romualdi was first to propose the use of steel fibers as a reinforcement material in his 1963 and 1964 papers. Since then, a plethora of books and papers have been published on the use of various fibers in cement-based material. Published literature shows huge potential of fibers as a reinforcement material. A comprehensive overview of the published literature on the use of fibers in cement-based material is being presented. Effect of fibers on properties of cement-based material such as workability, compressive strength, flexural strength, split tensile strength, shrinkage, impact resistance, fatigue behavior and durability has been presented.
\end{abstract}

Keywords: Fiber, volume fraction, polypropylene (PP), concrete, Polyethylene terephthalate(PET)

\section{Introduction}

Cement-based materials are world transforming man made construction materials. It consists of binding material (cement), sand and aggregate mixed with water such as concrete and mortar [4]. Concrete has excellent resistance to compression (crushing), but is very poor in tension (stretching). Its properties can be tailored according to need (strength, durability, etc). However it has low tensile strength, low ductility and low energy absorption. Due to its lack of tensile strength, it is reinforced with reinforcement bars or mesh in structures but this kind of reinforcement is ineffective for crack control. Concrete is basic in nature; reinforcement gets decayed and corroded in alkaline environments.

Fiber can be effectively used as a reinforcing material which posses certain characteristics.Romualdi and his co-authors were first to propose the use of steel fibers as a reinforcement material in concrete [48], since then various is literature published on use of different fibers. They are usually produced from glass, steel and other organic polymers. Figure (1-9) shows some fibers utilized in cementitious material [47] and Table 1 shows mechanical characteristics of various fibers [3]. Naturally occurring fibers such as sisal and coir are also utilized for reinforcement. Character of fiber reinforced concrete changes with the varying the material of fiber, densities, distribution and orientation. Generally, fiber's diameter and length do not exceed 0.04 in. and 3 in. respectively. Fibers are usually distributed uniformly and are present throughout the FRC, whereas wire or bars used foe reinforcement are placed only at some distinct positions.

Aspect ratio is usually employed to conveniently describe any fiber. The ratio of length of the fiber to its diameter is known as the aspect ratio of the fiber. Generally, fiber's aspect ratio does not exceed 75 in value.
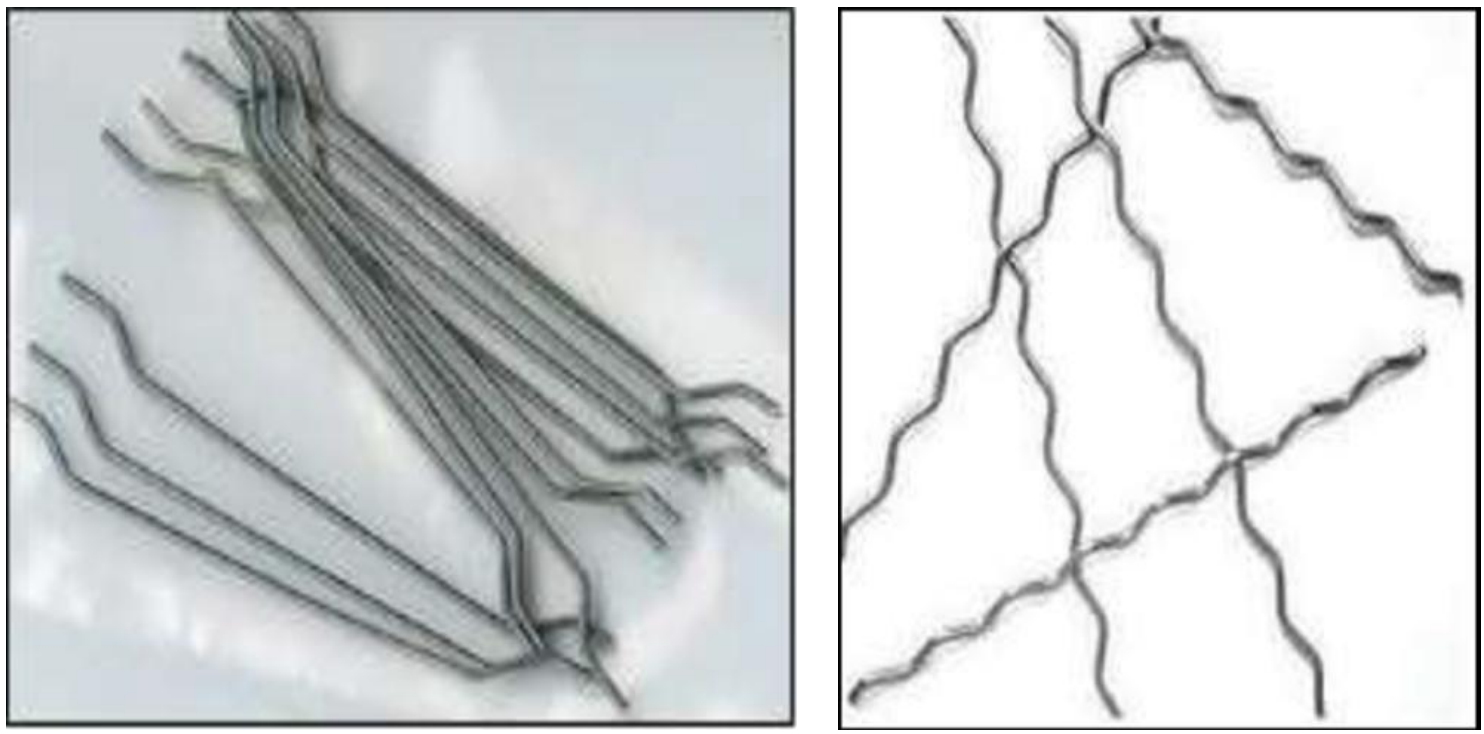

Figure 1: Hooked-end steel fiber Figure 2: Round steel fiber 


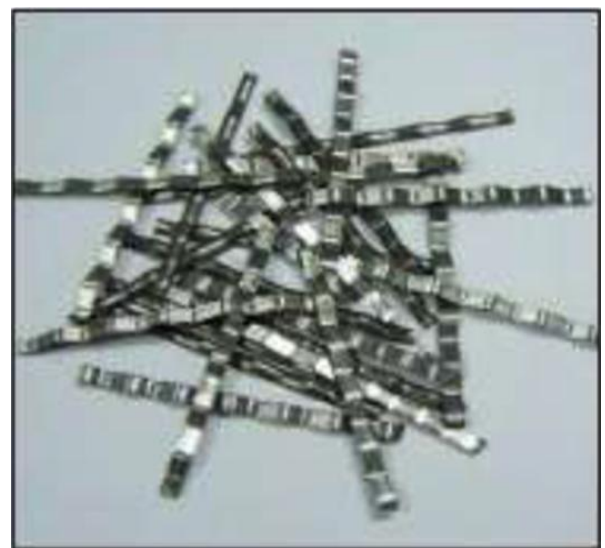

Figure 3 : Flat crimped steel fiber
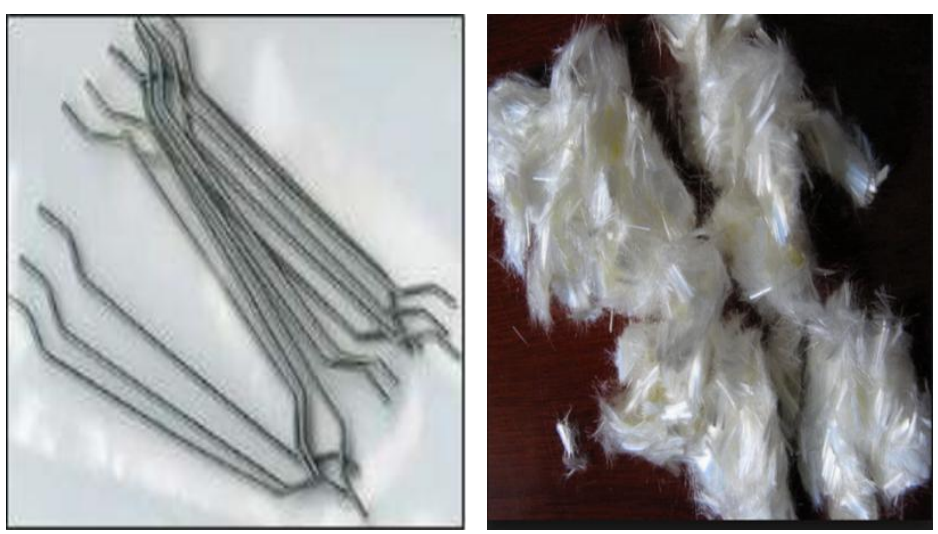

Figure 4 : Steel fiberFigure 5 : Polypropylene fiber
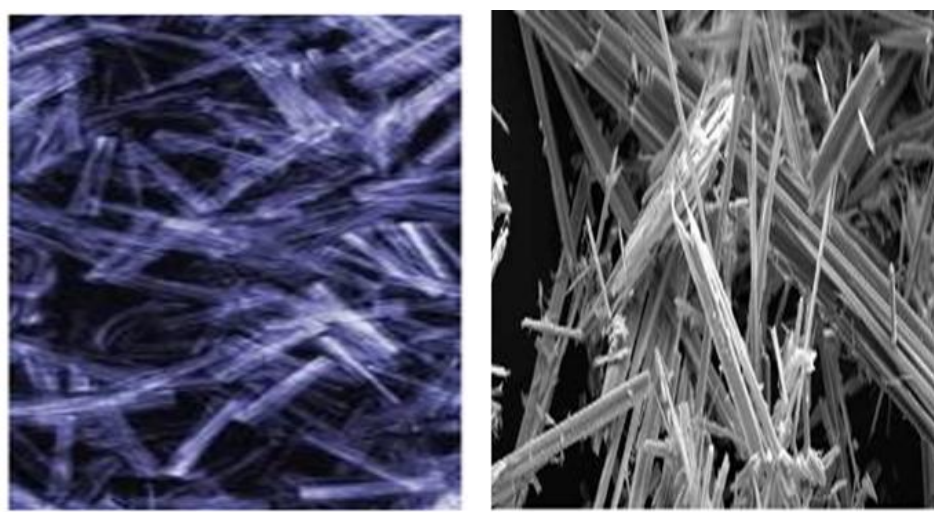

Figure 6 : Glass fiberFigure 7 : Asbestos fiber
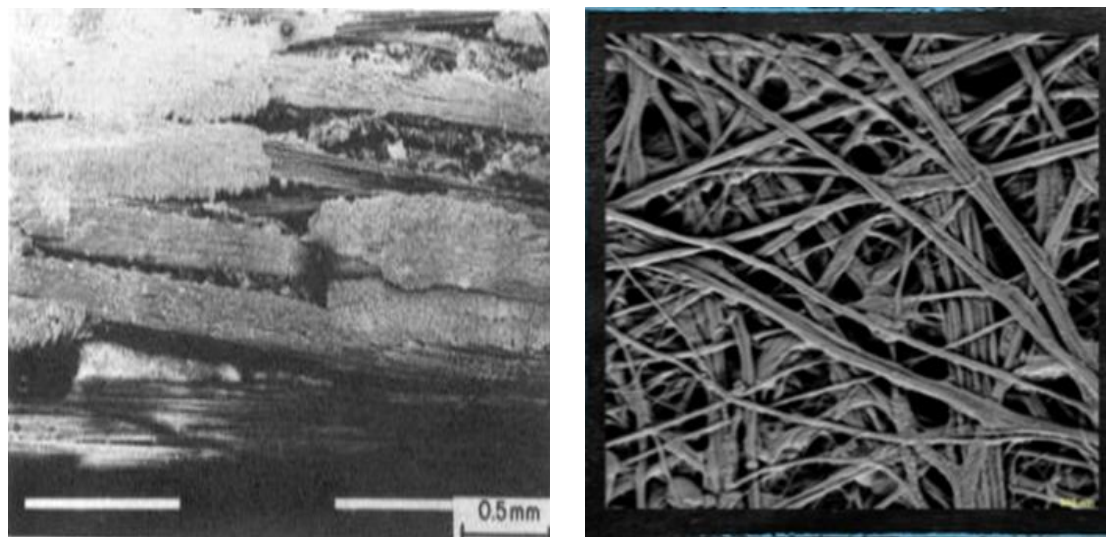

Figure 8 : Carbon fibFigure 9 : organic fiber 
Table 1: Mechanical characteristics of different fiber [3]

\begin{tabular}{|l|l|l|l|}
\hline Fiber type & Elastic modulus & Tensile strength & Ultimate elongation \\
\hline Steel & 200000 & $500-2000$ & $0.5-3.5$ \\
\hline Glass & $70000-80000$ & $2000-4000$ & $2-3.5$ \\
\hline Polypropylene & $5000-7000$ & $500-750$ & 8 \\
\hline Nylon & 4000 & 900 & $13-15$ \\
\hline Carbon & 230000 & 2600 & 1 \\
\hline
\end{tabular}

\section{Properties Of Concrete}

\subsection{Workability}

The effectiveness of all fiber reinforcement is particularly dependent upon accomplishment of a homogeneous spreading of the fibers in the concrete, successful casting and spraying and their interfacewith the cement. Adding more percentage of fibers especially which have small diameter, usually have a deteriorating effect on the workability of concrete and results in the requirement for changes in mix design. This is due to fibers with very small diameter have a much greater combined surface area. This extra demand on the addition of more water and cement or admixtures (hence increase in costs), will eventually result in dramatic effect on the workability of the concrete.

Peng Zhang and Qing-fu Li (2013)concluded that workability of concrete consisting of silica fumes and fly ash, decreases with addition of polypropylene fibers [1]. They further observed that the fluidity of fresh concrete decreases and the cohesiveness of fresh concrete composite increases with increase in fiber volume fraction.C.D. Atis and O. Karahan(2009) observed that the workability of mix reduces with surge in steel fiber content [2]. D. Foti (2013) observed that concrete mix is hardly workable when dosage of circular PET fibers exceed $1 \%$ by weight of concrete [3]. Even after employing superplasticizer, higher amount of fibers is not advisable because concrete is no longer workable. Y. Mohammadi et al (2008) investigated various properties of SFRC consisting fibers of different aspect ratio and compared it with plain concrete [12]. Conclusion argues that workability decreases uniformly with increase in fiber content.

Antonio Domingues de Figueiredoa and Marcos Roberto Ceccato (2015)observed that the fibers hindering the movement of the aggregate, chiefly results in loss of mobility and its intensity can be reduced by shortening the aspect ratio of the fibers [5]. But this also results in reduction of post crack strength of hardened fiber reinforced concrete. Conclusion argues to reduce the maximum size of aggregate or increase content of mortar in concrete.Faisal Fouad wafa (1990) studied that increase of fiber content from 0 to $2 \%$ results in decrease of slump value from $230 \mathrm{~mm}$ (for $0 \%$ ) to $20 \mathrm{~mm}$ (for $2 \%$ ) [6]. It was observed that the hooked fibers performed better when compared to straight fiber because balling was prevented during mixing.

N.A. Libre et al (2011) concluded that PP fibers have lesser effect on workability of fresh mix, when compared to steel fibers [15]. It was observed that the danger segregation in lightweight concrete reduces due to blocking effect by polypropylene and steel fibers.Chen and Liu (2005) observed that different fibers such as steel and polypropylene have a holding effect which reduces the sedimentation of aggregates, surface bleeding and enhanced uniformity in light weight concrete (LWC) [46]. It was also observed that highest decrease in slump was up to $54.2 \%$ due to inclusion of steel fibers in LWC.

\subsection{Compressive strength}

The ultimate resistance provided by the concrete block just before yielding to the exerted compressive load can be termed as the compressive strength of the concrete. While the plain concrete failed catastrophically during the compression tests, Brandt (2008) advocated thatplastic fiber reinforced concrete fails with occurrence of plentiful minor cracks on the surface [9]. S. Spadea et al (2015) investigated that incorporation of very short recycled nylon fibers decreases the compressive strength of inspected mortar (up to -37\%) [7]. S.B. Kim et al (2009)observed decrease in compressive strength of about 1 to $9 \%$ and of about 1 to $10 \%$ for recycled Polyethylene terephthalate(PET) and polypropylene fiber reinforced specimen when compared to the plain specimen, respectively [8].

C.D. Atis and O. Karahan(2009) investigated compressive strength at 7, 28, 90 and 365 days period [2]. They observed rise up to $10 \%$ and fall up to $6 \%$ in compressive strength of concrete specimen reinforced with steel fibers. Conclusion argues that variation is due to complications in providing a homogeneous spreading of fibers inthe specimen. D. Foti (2013)concluded that concrete containing circular PET fibers do not exhibit any significant increase in compressive strength [3].D.A. silva et al (2005) observed that addition of polyethylene terephthalate (PET) fibers had no significant effect on the compressive strength of mortar [10].

A. Alavi Nia et al (2012)studied that the compressive strength of FRC increases with increase in volume of fiber [11]. Increase of about $14.2 \%$ in compressive strength was observed when results were compared to plain concrete. Y. Mohammadi et al (2008) observed 26\% maximum increase in compressive strength against $2 \%$ fiber volume fraction of steel fibers [12]. This percentage of fiber was reported to be optimum volume fraction. H.T Wang and L.C Wang (2013)conducted experimental investigation on light weight concrete reinforced with 
volume fraction $(0.0 \%, 0.5 \%, 1.0 \%, 1.5 \%$ and $2.0 \%)$ of fibers [13]. It was concluded that compressive strength improved to some extent with the inclusion of steel fibers.

Faisal Fouad Wafa (1990)reported that essentially no impact on compressive strength of concrete was observed due to percentage of fiber volume fraction [6]. Patil Shweta and RupaliKavilkar (2014)observed thatcompressive strength decreased up to $31.10 \%$ with incorporation of steel fibers [14]. This maximum drop was observed for $1.5 \%$ fiber volume fraction. N.A. Libre et al. (2011)examined effect of the steel fiber on compressive strength of concrete. It was observed that compressive strength of concrete reduced to $50 \%$ with addition of steel fibers [15].

C. SelinRavikumar and T.S. Thandavamoorthy(2013) observed that compressive strength of concrete reinforced with glass fiber increases continuously with increase in fiber content [36].A.M Shende et al (2012) conducted experimental investigation on concrete with varying steel fiber content $(0 \%, 1 \%, 2 \%$ and $3 \%)$. It was reported that with increase of fiber content, compressive strength also increases [16].PS song et al (2005) conducted comparative experimental investigation of nylon fiber reinforced concrete and polypropylene fiber reinforced concrete.It was observed that nylon fiber improved the compressive strength of concrete by $6.3 \%$ when compared to PP reinforced concrete [17]. The increase was due to better distribution and superior tensile strength of nylon fibers.

Alhozaimy et al (1996) investigated the effect of various PP fiber content $(0 \%, 0.05 \%, 0.1 \%, 0.2 \%$ and $0.3 \%$ ) on the compressive strength of plain concrete along with concrete having various binders (silica fumes, fly ash and slag) [20]. No substantial effect was observed on plain concrete, while concrete with silica fumes demonstrated increase in strength up to $23 \%$.

\subsection{Flexural strength}

Flexural strength is the resistance offered by the concrete block just before failing under the application of bending (flexure) stresses induced by appropriate loading. S.B. Kim et al (2009) reported an increase of 25\%, $31 \%$ and $32 \%$ in flexural strength of recycled PET reinforced specimen at $0.5 \%, 0.75 \%$ and $1.0 \%$ of fiber volume fraction respectively [8]. C.D. Atis and O. Karahan(2009)reported that no substantial effect was observed on flexural strength at low volume fractions of steel fibers(up to $0.5 \%$ ) [2]. However, at $1.0 \%$ volume fraction, improvement was observed and flexural strength increased up to $15 \%$ and further surged up to $30-66 \%$ at volume fraction of $1.5 \%$. D. Foti (2013)concluded that concrete containing circular PET fibers do not exhibit any significant increase in flexural strength [3].D.A. silva et al (2005)studied that no substantial effect on tensile strength of mortar was observed when PET fibers were included [10]. Reason states that the strength to the first crack is in close relationship with the resistance offered by the plain mortar. H.T Wang and L.C Wang (2013)observed that theflexural strength was largely improved by the inclusion of steel fibers [13]. This effect was attributed to the ability of steel fibers to arrest the cracks.

Y. Mohammadi et al (2008) observed thatthe ultimate increase of $100 \%$ in static flexural strength was observed at fiber volume fraction of $2.0 \%$ with $100 \%$ long steel fibers in concrete [12].Faisal fouadwafa (1990) studied that optimum increase in flexural strength of $67 \%$ was observed at addition of $1.5 \%$ hooked fibers [6]. Incorporation of $2 \%$ straight fibers, increased flexural strength up to $40 \%$ compared to plain concrete. At $2 \%$ volume fraction of hooked fibers, drop in flexural strength was reported due to difficulties in consolidation and achievement of uniform distribution. Patil Shweta and RupaliKavilkar (2014)studied SFRC by keeping volume fraction of fiber constant at $1.5 \%$ and increasing the aspect ratio up to 70 increase up to $58.65 \%$ was observed in flexural strength [14]. Further by keeping aspect ratio constant at 70 and increased volume fraction of fibers up to $2.5 \%$, increase up to $119.69 \%$ was observed in flexural strength. N.A. Libre et al. (2011)studied that up to $200 \%$ increase in flexural strength was observed by addition of steel fibers [15]. Furthermore, some improvement in flexural strength was also observed by addition of $0.4 \%$ polypropylene fibers. C. SelinRavikumar and T.S. Thandavamoorthy (2013) studied with $0.5 \%$ volume fraction addition of glass fiber, $42 \%$ enhancement in flexural strength was observed and $75 \%$ increase in flexural strength was reported at $1 \%$ volume fraction addition [36].

A.M Shende et al (2012) observed that flexure strength is more at 3\% volume fraction addition of fibers compared to $0 \%, 1 \%$ and $2 \%$ fibers [16]. Moreover, the flexure strength augmentedup to $49 \%$ when steel fibers were included.Alhozaimy et al (1996) investigated the effect of various PP fiber content $(0 \%, 0.05 \%$, $0.1 \%, 0.2 \%$ and $0.3 \%$ ) on the flexural strength of plain concrete along with concrete having various binders (silica fumes, fly ash and slag) [20]. At $99 \%$ confidence level, it was observed that strength surged up to $387 \%$ with inclusion of $0.3 \%$ fiber content. While at $95 \%$ confidence level no considerable effect was observed.

\subsection{Tensile strength}

Resistance offered by the material against the longitudinal stresses, measured in terms of value of longitudinal stress required to rupture the material is commonly known as tensile strength of the material. S. Spadea et al (2015) reported that up to $35 \%$ improvement in tensile strength and enhancement of fracture 
properties of cement mortar was observed by addition of R-Nylon fibers [7].C.D. Atis and O. Karahan (2009) observed that splitting tensile strength increased up to $3 \%, 5 \%, 32 \%$ and $71 \%$ for concrete with and without fly ash having fiber volume fraction of $0.25 \%, 0.5 \%, 1 \%$ and $1.5 \%$ respectively [2].A. Alavi Nia et al (2012)observed that with increase in volume fraction of steel fiber, the tensile strength of concrete (up to $+62.1 \%$ ) also increases [11].

H.T Wang and L.C Wang (2013)studied that thesplitting tensile strength greatly improved by the addition of steel fibers, and variation from 3.99 MPa to 7.68 MPa was observed in tensile strength [13]. This increase was credited to the arresting of cracking by steel fibers. Y. Mohammadi et al (2008) studied that tensile strength increased up to $27 \%, 51 \%$ and $59 \%$ for volume fraction addition of $1.0 \%, 1.5 \%$ and $2 \%$ of steel fibers to the concrete mix respectively [12]. Mix ratio at $2 \%$ volume fraction containing $35 \%$ short fibers and $65 \%$ long fibers was credited to ultimate increase of 59\% in tensile strength. Faisal fouadwafa(1990)It was studied that maximum enhancement of $57 \%$ in tensile strength of concrete was observed at $1.5 \%$ volume fraction addition of steel fibers to the mix [6].N.A. Libre et al. (2011)reported thatinclusion of both steel and polypropylene fibers enhanced the tensile strength of light weight aggregate concrete up to $116 \%$ [8]. C. SelinRavikumar and T.S. Thandavamoorthy (2013)studied that with $0.5 \%$ volume fraction addition of glass fiber, $20 \%$ enhancement in tensile strength was observed and 37\% risein tensile strength was reported at $1 \%$ volume fraction addition [36].A.M Shende et al (2012)observed that tensile strength is more at 3\% volume fraction addition of fibers compared to $0 \%, 1 \%$ and $2 \%$ [16]. Moreover, the tensile strength augmented up to $49 \%$ when steel fibers were included.PS song et al (2005)observed that spitting tensile strength of nylon FRC enhanced by $6.7 \%$ over those of the polypropylene FRC [17]. The increase is due to slightly better dispersion of nylon fibers in the mixing water.

\subsection{Modulus of Elasticity}

Slope of stress-strain curve of the concrete, within the relative limit of the material effectively defines the modulus of elasticity of the concrete. Its value is constant for low level stresses but reduces when concrete cracks and higher level of stresses are developed. C.D. Atis and O. Karahan (2009) studied that concrete containing steel fiber volume fraction of $0.25 \%$ and $0.5 \%$ had marginally higher value of elastic modulus compared to concrete without fibers [2]. Generally, modulus of elasticity reduces with increase in fiber content. D.A. silva et al (2005) studied that PET fibers virtually had no significant effect on elasticity modulus of mortar in flexural test [10]. S.B. Kim et al (2009) observed that recycled Polyethylene terephthalate(PET) and polypropylene(PP) concrete had lower value of elastic modulus compared to the plain concrete [8]. It was also reported that modulus of elasticity decreased with rise in fiber content.

\subsection{Shrinkage Test}

When subjected to a drying environment, concrete has a tendency to shrink. Its extent depends up on variety of factors such as material properties, humidity and temperature, size of concrete specimen. If shrinkage is restrained, tensile stresses and cracks may occur. Cracking of walls, pavements and slabs mostly occurs due to shrinkage cracking. Peng Zhang and Qing-fu Li (2013) observed that increase in polypropylene fiber content of the concrete, decreases the dry shrinkage strain [1]. Increase in fiber volume fraction up to $0.12 \%$ resulted in $24 \%$ decrease in ultimate dry shrinkage strain of 90 days.

Malhotra et al (1994) studied that high volume fly ash concrete reinforced with polypropylene (PP) fibers, demonstrated decrease in property of drying shrinkage [18].Liu et al (2005) reported that cement mortar containing PP fibers, demonstrated decrease in property of drying shrinkage [21]. Salih and Al-Azaawee (2008)[22] and Okan and Cengiz (2011)[19]advocated this conclusion and stated that stitching and bridging of the fine cracks by the addition of PP fibers in mortar resulted in restraining of microlevel movements.

Mangat and Azari (1984)stated that fiber by making composite stiffer, stronger and restraining shrinkage by shear, decreases the dry shrinkage [23].C.D. Atis and O. Karahan (2009)studied that increase in steel fiber volume fraction results in reduction of drying shrinkage [2].S.B. Kim et al (2009)observed increase in free drying shrinkage strain when recycled Polyethylene terephthalate fibers were added in the concrete [8]. While for restrained shrinkage, fibers postponed the formation of cracks and improved tensile resistance.PS song et al (2005)observed that the nylon fiber in mortar has moderately better shrinkage crack reducing potential than that of the polypropylene fibers [17].Kim et al (2008) experimentally investigated result of recycled polyethylene terephthalate (PET) fiber orientation on the plastic shrinkage of the concrete [27]. Conclusion states that plastic shrinkage was affected by fiber geometry only when volume fraction of fiber was reasonably low (up to $0.25 \%$ ).

\subsection{Ductility}

Concrete is a brittle material and usually have no substantial post-cracking ductility. Addition of fiber is generally considered to increase the ductility of the material. S. Spadea et al (2015) concluded that the incorporation of recycled fibers to the mix resulted in improvement of ductility properties of concrete and 
mortar [7]. D. Foti (2013) studied that high volume fraction of fibers enhances ductile behavior of concrete [3]. But high dosage is not recommended because adherence of fibers with concrete is lost and workability is also reduced. Faisal fouadwafa (1990) observed thataddition of steel fibers enhances the ductility of concrete and also the capacity to carry post-cracking load [6].

Patil Shweta and RupaliKavilkar (2014) studied thatductile behavior of concrete improves by increasing the fiber volume fraction [14]. Maximum ductile behavior was observed at $2.5 \%$ fiber volume fraction with aspect ratio of 70.N.A. Libre et al. (2011)studiedthat addition of steel fiber in lightweight aggregate concrete (usually brittle), improves its ductile behavior [8].

\subsection{Fatigue Behavior}

Fatigue may be defined as a process of progressive, permanent internal structural changes in a material subjected to repeated loading. Fatigue failure strength is defined as the ultimate flexural fatigue stress at which the beam can withstand two million cycles of non-reversed fatigue loading [38].T. Brandshaug (1978) and R.F zollo (1975) advocated that the flexure fatigue strength of the concrete increases with increase in steel fiber volume fraction in concrete [42-43]. Cachim et al (2002) studied fatigue life of concrete reinforced with steel fibers of $30 \mathrm{~mm}$ and $60 \mathrm{~mm}$ in length [44]. Fatigue life was observed to increase for $30 \mathrm{~mm}$ fiber concrete, while it reduced for $60 \mathrm{~mm}$ fiber concrete. J. Zhang, H. Stang (1998) observed that incorporation of steel fiber substantially improved the bending fatigue performance of concrete [45].

\subsection{Toughness}

Toughness is the amount of energy per unit volume that a material can absorb before rupturing.S. Spadea et al (2015) concluded that the incorporation of recycled fibers to the mix resulted in enhancement of toughness properties of concrete and mortar [7]. D.A. silva et al (2005) observed that presence of PET fibers increases the toughness of mortar [10]. However, decrease in toughness with the age of fiber reinforced specimen was also reported. This is credited to deterioration of PET fibers inside mortar. Faisal fouadwafa (1990) observed that addition of hooked and straight fibers results in increase of toughness index of specimen [6]. Toughness index of specimen having hooked fibers was up to $65 \%$ more than the specimen containing straight fibers.

\subsection{Impact Resistance}

ACI committee 544 recommended that to assess the impact strength [38], repeated blows should be subjected. First crack strength is defined asthe number of blows required to produce first visible crack on the top of the specimen. Failure strength is the number of blows required for ultimate failure of the specimen. K. Marar et al (2001) observed that impact resistance increases with increase in steel fiber volume fraction for all aspect ratios [40]. Impact resistance of HSC increased up to 74 times when $2 \%$ volume fiber of aspect ratio- 83 was added.M. Nili (2010)Observed that addition of steel fibers improved the impact resistance of the concrete [39]. It was also reported that inclusion of silica fume along with steel fibers, further increased impact resistance. Alhozaimy et al (1996) observed improvement in impact resistance of concrete due to incorporation of polypropylene fibers. Impact resistance increased up to $171 \%$ by addition of $0.2 \%$ fiber content.

A. Alavi Nia et al (2012) experimentally and numerically studied that inclusion of either hooked-end steel fiber or PP fibers improved the impact resistance of concrete [20]. Steel fiber reinforced concrete was reported to have better impact resistance compared to PP fiber reinforced concrete.N. Banthia et al (1998) investigated response of steel and carbon fibers on impact resistance of mortar and concrete [41]. Significant improvement in impact resistance was observed by inclusion of fibers under both normal and low temperature.

\subsection{Durability}

\subsubsection{Effect of Alkaline Environment}

The deterioration of natural fibers engaged in Portland cement is the result of the high alkaline environment which dissolves the fiber and thus making the structure weak [24]. Gram H. (1983) investigated the fiber reinforced concrete incorporating coir and sisal fibers [25]. When specimen was exposed to alkaline solution, degradation of fibers was observed and variations in tensile strength were measured. $\mathrm{Ca}^{+2}$ ionswere reported to have negative effect on fibers. Toledo Filho et al. (2000) studied the durability of coconut and sisal fibers when conditioned with alkaline solutions [26]. Coconut and sisal fibers immersed in a sodium hydroxide $(\mathrm{NaOH})$ solutionmaintained respectively $60.9 \%$ and $72.7 \%$ of their original strength after a period of 420 days. For the fiber immersed in the $\mathrm{Ca}(\mathrm{OH})_{2}$ solution, author noted that original strength was entirely lost due to the crystallization of fiber pores after 300 days. Krishna and Sundararajan (2005) studied the durability of natural fibers and effect of corroded fiber on the strength of mortar [28]. They also reported that natural fibers deteriorated when exposed to an alkaline environment. 


\subsubsection{Freeze-Thaw Resistance}

Seeping of water inside the cracks of the specimen (such as concrete) and its freezing may result in breaking of that specimen. Hence the resistance offered by the specimen against the cyclic freezing and melting is termed as freeze-thaw resistance.Peng Zhang and Qing-fu Li (2013) experimentally observed the effect of varying volume fraction of fiber in FRC [1]. It was observed that freeze-thaw resistance increases up to .08\% fiber volume fraction and decreases when it is increased from $0.8 \%$ to $0.12 \%$. Conclusion argues that when volume of fiber increases the space between fibers decreases. Therefore, increasing the number of weak interface and overlapping of interface area of adjacent fibers. Thus interface area of micro structure tends to be very loose, which reduces the freeze-thaw durability of concrete.

C.D. Atisand O. Karahan (2009)reported that concrete specimen with steel fibers has slightly better freeze-thaw resistancewhen compared plain concrete [2]. D. Niu et al (2013) investigated thatthe steel fiber volume fraction hashuge effect on the frost-resisting capacity of steel fiber reinforced concrete [29]. When a steel fiber content of $1.5 \mathrm{vol} \%$ is introduced, the frost damage is considerably reduced. However, concrete's frost-resisting property significantly decreased with $2 \%$ steel fiber content.

\subsubsection{Permeability}

Applied load and various other forms of stresses such as thermal, mechanical and chemical may result in growth of cracks and thus in turn increase the permeability of concrete specimen. This increase in permeability leads to deterioration of the specimen.Peng Zhang and Qing-fu Li (2013)experimentally studied that concrete specimen containing silica fume and fly ash was observed to have a reduction in permeability when polypropylene(PP) fibers were included [1]. It was also observed that as fiber volume fraction increases permeability of mix decreases.

A.P. Singh and DhirendraSinghal (2011) reported that the permeability reducedconsiderably with rise in fiber content and escalating curing age [31]. The change in aspect ratio does not have a considerable effect on the water permeability of steel fiber reinforced concrete.

\subsubsection{Carbonation Depth}

The carbonation resistance of concrete can be determined by carbonation depth of specimen under the action of $\mathrm{CO}_{2}$ pressure, process is to diffuse $\mathrm{CO}_{2}$ from the surface to inside of the specimen and the as the diffusion depth of $\mathrm{CO}_{2}$ increases, the carbonation depth also increases.Peng Zhang and Qing-fu Li (2013) observed that Carbonation resistance is increasing uniformly with the increase of volume fraction of polypropylene fibers [1]. Roziere et al (2009) advocated it and stated that fibers block the capillary channels in the mortar and makes capillary pores smaller [31]. Moreover, fibers reduce diffusion channels of $\mathrm{CO}_{2}$ by reducing micro cracks in concrete.

\subsubsection{Fire Resistance}

Fire resistance is the ability of concrete to effectively perform its function of load bearing and fireseparating during fire exposure. Explosive spalling and other unique behavior is shown by HSC under elevated temperatures. This behavior has been credited to dense concrete structure of High strength concrete.. Chen and Liu (2004) experimentally investigated specimen at $20^{\circ} \mathrm{C}, 200^{\circ} \mathrm{C}, 400^{\circ} \mathrm{C}, 600^{\circ} \mathrm{C}$ and $800^{\circ} \mathrm{C}$ and concluded that explosive spalling is present for ordinary high strength concrete [33]. Strength left in the concrete (residual strength) is merely $10 \%$ of original strength at $800^{\circ} \mathrm{C}$. It was observed that delay in time when spalling occurs can be increased by addition of steel and carbon fibers in high strength concrete. When temperature ranged $400^{\circ} \mathrm{C}-600^{\circ} \mathrm{C}$,no substantial decrease in strength was observed but when temperature exceeds $600^{\circ} \mathrm{C}$ and reaches $800^{\circ} \mathrm{C}$, its residual strength was still $30 \%$ of original strength. Dale P. Bentz(2000)suggested the reason that PP fibers enhances the performance level because when specimen is exposed to fire, water vapors is generated by the thermal breakdown of hydrated cement paste and burning of fibers provides a conduit for the release of the water vapor [34].

AminuddinJamerana et al (2015)studied the effect of elevated temperature on steel and PP fiber reinforced concrete [35]. The addition of steel and polypropylene fibers into the concrete mixture minimized the effects by reducing crack growth in the concrete. They also reported that steel fibers are better than PP fibers. C. SelinRavikumar and T.S. Thandavamoorthy (2013)heated glass fiber reinforced concrete with different volume fraction $(0 \%, 0.5 \%$ and $1 \%)$ for $2 \mathrm{hrs}$ [36]. Decrease in compressive strength to its original strength is $32 \%, 25 \%, 10 \%$ for $0 \%, 0.5 \%$ and $1 \%$ fiber volume fraction respectively.

\section{Observations}

Fiber volume fraction in the cement-based material greatly influences the fresh and hardened properties of the material. The published literature shows that presence of fibers in the specimen influences the workability of fresh mix, durability and strength of hardened material. 


\section{Conclusion}

Conclusions drawn from reviewing the published literature are: -

- Workability of the fresh mix is adversely affected by the addition of fibers and further decreases by increasing the fiber volume fraction.

- No particular trend is observed in compressive strength due to addition of fibers. Different fibers have different responses to the strength of the specimen.

- Flexural and tensile strength, ductility, drying shrinkage and toughness of the material is usually benefited by the addition of fibers.

- Use of fibers in the cement-based material improves its durability. It has been well established by observing improvement in various tests such as freeze-thaw resistance, permeability, carbonation depth and fire resistance.

Fiber reinforcement can be utilized in development of high and ultra-high performance concrete. But proper execution and competent design are necessary to maintain the performance of fiber reinforced cementbased material.

\section{Future Scope}

Though published literature very well establishes the utility and feasibility of different fibers in cementitious material, following are the possibilities and recommendation for future research:

1. Assessing micro structure of the fiber reinforced cement-based material using various techniques like SEM and XRD.

2. Developing a standard test procedure for fatigue and impact loading to evaluate performance difference among different types of fibers.

3. Investigating various methods to modify bond between matrix and steel fibers.

\section{References}

[1]. Zhang, P., \& Li, Q. F. (2013). Effect of polypropylene fiber on durability of concrete composite containing fly ash and silica fume. Composites Part B: Engineering, 45(1), 1587-1594..

[2]. Atiş, C. D., \&Karahan, O. (2009). Properties of steel fiber reinforced fly ash concrete. Construction and Building Materials, 23(1), 392-399.

[3]. Foti, D. (2013). Use of recycled waste pet bottles fibers for the reinforcement of concrete. Composite Structures, 96, 396-404.

[4]. Singh, S., Khan, S., Khandelwal, R., Chugh, A., \& Nagar, R. (2016). Performance of sustainable concrete containing granite cutting waste.Journal of Cleaner Production, 119, 86-98

[5]. Figueiredo, A. D. D., \&Ceccato, M. R. (2015). Workability Analysis of Steel Fiber Reinforced Concrete Using Slump and Ve-Be Test. Materials Research,18(6), 1284-1290.

[6]. Wafa, F. F. (1990). Properties \& Applications of Fiber Reinforced Concrete.Engineering Sciences, 2(1)

[7]. Spadea, S., Farina, I., Carrafiello, A., \&Fraternali, F. (2015). Recycled nylon fibers as cement mortar reinforcement. Construction and Building Materials, $80,200-209$

[8]. Kim, S. B., Yi, N. H., Kim, H. Y., Kim, J. H. J., \& Song, Y. C. (2010). Material and structural performance evaluation of recycled PET fiber reinforced concrete. Cement and concrete composites, 32(3), 232-240.

[9]. Brandt, A. M. (2008). Fibre reinforced cement-based (FRC) composites after over 40 years of development in building and civil engineering. Composite structures, 86(1), 3-9.

[10]. Silva, D. A. D., Betioli, A. M., Gleize, P. J. P., Roman, H. R., Gomez, L. A., \& Ribeiro, J. L. D. (2005). Degradation of rec ycled PET fibers in Portland cement-based materials. Cement and Concrete Research, 35(9), 1741-1746.

[11]. Nia, A. Alavi, M. Hedayatian, M. Nili, and V. AfroughSabet. "An experimental and numerical study on how steel and polypropylene fibers affect the impact resistance in fiber-reinforced concrete." International Journal of Impact Engineering 46 (2012): 62-73.

[12]. Mohammadi, Y., Singh, S. P., \& Kaushik, S. K. (2008). Properties of steel fibrous concrete containing mixed fibres in fresh and hardened state.Construction and Building Materials, 22(5), 956-965.

[13]. Wang, H. T., \& Wang, L. C. (2013). Experimental study on static and dynamic mechanical properties of steel fiber reinforced lightweight aggregate concrete. Construction and Building Materials, 38, 1146-1151.

[14]. Patil Shweta and RupaliKavilkar. "Study of Flexural Strength in Steel Fibre Reinforced Concrete". International Journal of Recent Development in Engineering and Technology, ISSN 2347 - 6435 (Online) Volume 2, Issue 5, May 2014

[15]. Libre, N. A., Shekarchi, M., Mahoutian, M., \&Soroushian, P. (2011). Mechanical properties of hybrid fiber reinforced lightweight aggregate concrete made with natural pumice. Construction and Building Materials,25(5), 2458-2464.

[16]. Shende, A. M., Pande, A. M., \&Pathan, M. G. (2012). Experimental Study on Steel Fiber Reinforced Concrete for M-40 Grade. International Refereed Journal of Engineering and Science, 1(1), 043-048.

[17]. Song, P. S., Hwang, S., \&Sheu, B. C. (2005). Strength properties of nylon-and polypropylene-fiber-reinforced concretes. Cement and Concrete Research, 35(8), 1546-1550.

[18]. Malhotra, V. M., Carette, G. G., \&Bilodeau, A. (1994). Mechanical properties and durability of polypropylene fiber reinforced high-volume fly ash concrete for shotcrete applications. Materials Journal, 91(5), 478-486.

[19]. Karahan, O., \&Atiş, C. D. (2011). The durability properties of polypropylene fiber reinforced fly ash concrete. Materials \& Design, 32(2), 1044-1049.

[20]. Alhozaimy, A. M., Soroushian, P., \& Mirza, F. (1996). Mechanical properties of polypropylene fiber reinforced concrete and the effects of pozzolanic materials. Cement and Concrete Composites, 18(2), 85-92.

[21]. LIU, L. F., WANG, P. M., \& YANG, X. J. (2005). Effect of polypropylene fiber on dry-shrinkage ratio of cement mortar. Journal of Building Materials, 4, 373-377. 
[22]. Salih SA, Al-Azaawee ME. Effect of polypropylene fibers on properties of mortar containing crushed bricks as aggregate. EngTechnol 2008;26(12):1508-23.

[23]. Mangat, P. S., \& Azari, M. M. (1984). A theory for the free shrinkage of steel fibre reinforced cement matrices. Journal of materials science, 19(7), 2183-2194.

[24]. Pacheco-Torgal, F., \&Jalali, S. (2011). Cementitious building materials reinforced with vegetable fibres: A review. Construction and Building Materials, 25(2), 575-581..

[25]. Gram H. Durability of natural fibres in concrete. Stockolm: Swedish Cement and Concrete Research Institute; 1983

[26]. Toledo Filho, R. D., Scrivener, K., England, G. L., \& Ghavami, K. (2000). Durability of alkali-sensitive sisal and coconut fibres in cement mortar composites. Cement and Concrete composites, 22(2), 127-143.

[27]. Kim, J. H. J., Park, C. G., Lee, S. W., Lee, S. W., \& Won, J. P. (2008). Effects of the geometry of recycled PET fiber reinforcement on shrinkage cracking of cement-based composites. Composites Part B: Engineering,39(3), 442-450.

[28]. Ramakrishna, G., \& Sundararajan, T. (2005). Studies on the durability of natural fibres and the effect of corroded fibres on the strength of mortar.Cement and Concrete Composites, 27(5), 575-582..

[29]. Niu, D., Jiang, L., Bai, M., \& Miao, Y. (2013). Study of the performance of steel fiber reinforced concrete to water and salt freezing condition. Materials \& Design, 44, 267-273.

[30]. Bagherzadeh, R., Sadeghi, A. H., \&Latifi, M. (2011). Utilizing polypropylene fibers to improve physical and mechanical properties of concrete. Textile Research Journal, 0040517511420767.

[31]. Singh, A. P., \&Singhal, D. (2011). Permeability of steel fibre reinforced concrete influence of fibreparameters. Procedia Engineering, 14, 2823-2829.

[32]. Roziere, E., Loukili, A., \&Cussigh, F. (2009). A performance based approach for durability of concrete exposed to carbonation. Construction and Building Materials, 23(1), 190-199.

[33]. Chen, B., \& Liu, J. (2004). Residual strength of hybrid-fiber-reinforced high-strength concrete after exposure to high temperatures. Cement and Concrete Research, 34(6), 1065-1069.

[34]. Bentz, D. P. (2000). Fibers, percolation, and spalling of high-performance concrete. ACI Materials Journal-American Concrete Institute, 97(3), 351-359.

[35]. AminuddinJamerana, Izni S. Ibrahima, SitiHamizah S. Yazan, Siti Nor A. A. Rahim(2015) Mechanical properties of steelpolypropylene fibre reinforced concrete under elevated temperature The 5th International Conference of Euro Asia Civil Engineering Forum (EACEF-5) Procedia Engineering 125 ( 2015 ) 818 - 824

[36]. Ravikumar, C. S., \&Thandavamoorthy, T. S. (2011). Glass Fibre Concrete: Investigation on Strength and Fire Resistant Properties. IOSR Journal of Mechanical and Civil Engineering (IOSR-JMCE), 9(3).

[37]. Singh, S., Nagar, R., \& Agrawal, V. (2016). A review on Properties of Sustainable Concrete using granite dust as replacement for river sand.Journal of Cleaner Production, 126, 74-87..

[38]. ACI Committee 544. State-of-the-art report on fiber reinforced concrete.ACI Committee 544 report 544.1R-96 American Concrete Institute, Detroit (1996)

[39]. Nili, M., \&Afroughsabet, V. (2010). Combined effect of silica fume and steel fibers on the impact resistance and mechanical properties of concrete.International journal of impact engineering, 37(8), 879-886.

[40]. Marar, K., Eren, Ö., \&Celik, T. (2001). Relationship between impact energy and compression toughness energy of high-strength fiber-reinforced concrete. Materials letters, 47(4), 297-304.

[41]. Banthia, N., Yan, C., \& Sakai, K. (1998). Impact resistance of fiber reinforced concrete at subnorma temperatures. Cement and Concrete Composites, 20(5), 393-404.

[42]. Brandshaug, T.; Ramakrishnan, V.; Coyle, W. V.; and Schrader, E.K., "A Comparative Evaluation of Concrete Reinforced with StraightSteel Fibers and Collated Fibers with Deformed Ends." Report No.SDSM\&T-CBS 7801, South Dakota School of Mines and Technology, Rapid City, May 1978, 52 pp.

[43]. Zollo, Ronald F., "Wire Fiber Reinforced Concrete Overlays forOrthotropic Bridge Deck Type Loadings," ACI JOURNAL, Proceedings, Vol. 72, No. 10, Oct. 1975, pp. 576-582.

[44]. Cachim, P. B., Figueiras, J. A., \& Pereira, P. A. (2002). Fatigue behavior of fiber-reinforced concrete in compression. Cement and concrete composites, $24(2), 211-217$

[45]. J. Zhang, H. Stang. Fatigue performance in flexure of fiber reinforced concrete. ACI Mater. J., 95 (1) (1998), pp. $58-67$.

[46]. Chen, B., \& Liu, J. (2005). Contribution of hybrid fibers on the properties of the high-strength lightweight concrete having good workability. Cement and Concrete Research, 35(5), 913-917.

[47]. Divyeshkumar D. Paradaval and Prof. Jayeshkumar Pitroda. "Utilization Of Artificial Fibres In Construction Industry: A Critical Literature Review". fibre International Journal of Engineering Trends and Technology (IJETT), ISSN: 2231-5381 Volume 4 Issue 10 - Oct 2013.

[48]. Romualdi JP, Batson GB. Mechanics of crack arrest in concrete. J EngMechDivASCE Proc 1963;89(EM3):147-68. 